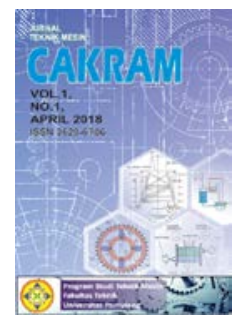

\title{
KOROSI BAJA TAHAN KARAT AISI 410 DI DALAM LARUTAN BRINE BUATAN
}

\author{
Moch. Syaiful Anwar ${ }^{1}$ \\ ${ }^{1}$ Program Studi Teknik Mesin, Universitas Pamulang, Jl. Surya Kencana No. 1, Tangerang Selatan, Indonesia \\ E-mail : dosen01625@unpam.ac.id
}

Masuk : 5 Agustus 2019 Direvisi : 12 September $2019 \quad$ Disetujui : 8 Oktober 2019

\begin{abstract}
Abstrak:Baja AISI 410 adalah baja tahan karatmartensitik yang umumnya digunakan sebagai komponenvalve, pompa dan turbin.Penelitian ini bertujuan untuk menghitung laju korosi pada baja tahan karat AISI 410 pada proses pembentukan yang berbeda (Standar, casting dan forging) di dalam media larutan brine buatan. Sampel baja AISI 410 standar, casting, dan forging di potong dengan ukuran yang sama yaitu $1 \mathrm{~cm}$. Kemudian permukaan sampel-sampel baja AISI 410 dihaluskan menggunakan kertas amplas sampai grit 800. Setelah itu, sampel-sampel baja direndam didalam larutan brine buatan dengan dialiri gas $\mathrm{CO}_{2}$ selama 13 hari. Perubahan nilai $\mathrm{pH}$ larutan brine buatan dan potensial sirkuit bebas diukur setiap hari selama 12 hari. Pada hari ke 13 dilakukan penimbangan berat pada masing-masing sampel. Hasilpada sampel baja AISI 410 hasil proses forging mengalami penambahan berat yg cukup tinggi dari pada sampel lainnya.
\end{abstract}

Kata Kunci: Baja AISI 410, martensitik, larutan brine buatan, standar, casting, forging, pH, laju korosi.

Abstract:AISI 410 steel is a martensitic stainless steel material commonly used to component of valve, pump and turbine. The purpose was to calculate the corrosion rate in stainless steel AISI 410 in different forming processes (Standard, casting and forgings) in artificial brine solution media. AISI 410 steel samples ofstandard, casting, and forgings are cut to the same size, 1 $\mathrm{cm}$. Then the surface of AISI 410 steel samples was ground using sandpaper up to 800 grits. After that, steel samples were immersed in artificial brine solution with CO2 gas flowed for 13 days. Changes in the $\mathrm{pH}$ value of artificial brine solution and open circuit potential are measured every day for 12 days. On the 13th day, we weighing to each sample. The results of the AISI 410 steel sample from the forging process experienced a considerable increase in weight compared to the other samples.

Keywords: AISI 410 steel, martensitic, artificial brine solution, satndard, casting, forging, pH, corrosion rate.

\section{PENDAHULUAN}

Pada tahun 1918, sumber energi panasbumi pertama kali dilakukan eksplorasi di Kawah Kamojang, Jawa Barat. Sebanyak lima sumur eksplorasi dibor dalam kurun waktu 1926-1929.Salah satunya adalah sumur KMJ-3 yang menghasilkan uap panas kering atau dry steamsampai saat ini. Namun, eksplorasi selama tiga tahaun tersebut dihentikan hingga Indonesia mendapatkan kemerdekaannya. Pada tahun 1972, kegiatan eksplorasi panasbumi di Indonesia dilakukan kembali secara luas. Kegiatan tersebut diinisiasi oleh kerja sama antara Direktorat Vulkanologi dan Mitigasi Bencana-ESDM dan Pertamina, dengan Pemerintah Perancis dan New Zealand untuk melakukan surveydi seluruh wilayah Indonesia. Berdasarkan hasil survey didapatkan bahwa terdapat 217 titik sumber panasbumi, yaitu sepanjang jalur vulkanikdari bagian Barat Sumatera, Pulau Jawa, Bali, Nusatenggara dan kemudian membelok ke arah utara melalui Maluku dan Sulawesi. Pada survey berikutnyaterdapat sumber panas bumi baru sebayak 256 titik, yaitu 84 titik di Sumatera, 76 titik diJawa, 51 titik di Sulawesi, 21 titik di Nusa Tenggara, 3 titik di Papua, 15 titik di Maluku dan5 titik di Kalimantan. Sistem panas bumi umumnya menggunakansistem hidrothermaldimana temperaturnyalebih dari $225^{\circ} \mathrm{C}$ dan sedikit yang memiliki temperatur $150-225^{\circ} \mathrm{C}[1]$.

Moch. Syaiful Anwar, Korosi Baja Tahan Karat AISI 410 di dalam Larutan Brine Buatan 
Menurut Budihardi (1998) terjadinya sumber energi panasbumi di Indonesia serta karakteristiknya disebabkan karena adanya interaksi antar lempengan di Indonesia. Sebanyak3 (tiga) lempengan yang ada dan masih aktifdi Indonesia, adalah lempeng Pasifik, lempeng India-Australia dan lempeng Eurasia. Interaksi tersebut menghasilkan tumbukan (impact)antar ke-tiga lempeng tektonik yang berdampak pada terbentuknya sumber energi panas bumi di Indonesia[1].

Baja tahan karat(stainless steel) banyak digunakan karena memiliki sifat tahan terhadap korosi (suhu, $\mathrm{pH}$, dan kelembaban udara).Banyaknya pengggunaan stainless steel dalam industri karena sifatnya yang tahan oksidasi.Penggunaan stainless steel ini bertujuan untuk meningkatkan efisiensi kerja dan salah satu langkah untuk menghemat biaya [2].

Baja stainless steel AISI 410umumnya diaplikasikandi bidang industri dan kesehatan. Aplikasi di bidang industri sepertivalve, pompa dan turbin, sedangkan di bidang kesehatan seperti peralatan bedah, pisau dan gunting bedah. Baja AISI 410 memiliki sifat mekanik danketahanan korosi yang cukup baik [3]. Upaya meningkatkan sifat ketahanan korosibaja AISI 410 dapat dilakukan dengan menggunakan metode electroplating.Electroplatingadalah proses modifikasi permukaan material dengan cara pelapisan logam. Sistem sirkuit terdiri dari arus searah (Direct Current), anoda, katoda dan larutan elektrolit.Arus DC dialirkan ke kedua elektroda didalam larutan elektrolit, sehingga muatan ion positif akan ditarik oleh elektroda didalam larutan elektrolit yang kemudian akan didepositkan pada katoda [4, 5].Tujuan dari penelitian ini adalah untuk menghitung laju korosi pada baja tahan karat AISI 410 pada proses pembentukan yang berbeda (Standar, casting dan forging) di dalam media larutan brine buatandengan dialiri gas $\mathrm{CO}_{2}$ dimana komposisi kimia larutan tersebut menyerupai larutan brine di Pembangkit Listrik Panas bumi (PLTP).

\section{METODOLOGI}

Bahan-bahan penelitian yang digunakan dalam penelitian ini yaitu

1. Baja AISI 410yang terdiri atas tiga sampel yaitu, standar dengan luas permukaan $2,55 \mathrm{~cm}^{2}$, casting dengan luas permukaan $3,4 \mathrm{~cm}^{2}$,dan forging dengan luas permukaan $1,95 \mathrm{~cm}^{2}$. Ketiga sampel tersebut memiliki komposisi kimia yang berbeda-beda. Tabel 1. Komposisi kimia dari ketiga sampel.

Tabel 1. Komposisi dari sampel

\begin{tabular}{lcccc}
\hline No & Unsur Kimia & Standar (berat \%) & casting (berat \%) & forging (berat \%) \\
\hline 1 & $\mathrm{C}$ & 0,07002 & 0,07408 & 0,1 \\
2 & $\mathrm{~S}$ & 0,0048 & 0,0000 & 0,005 \\
3 & $\mathrm{P}$ & 0,0221 & 0,0092 & 0,002 \\
4 & $\mathrm{Mn}$ & 0,29750 & 0,59093 & 0,61 \\
5 & $\mathrm{Si}$ & 0,44183 & 0,43953 & 0,24 \\
6 & $\mathrm{Cr}$ & 10,93408 & 12,45719 & 12,73 \\
7 & $\mathrm{Mo}$ & 0,00827 & 2,70259 & 2,52 \\
8 & $\mathrm{Ni}$ & 0,11516 & 2,97479 & 2,93 \\
9 & $\mathrm{Fe}$ & $\mathrm{Bal}$ & $\mathrm{Bal}$ & Bal \\
\hline
\end{tabular}

2. Lalarutan brine buatan, yang diguanakan untuk merendam sebanyak 1 liter.larutan brine menggunakan standar ASTM D1141.Komposisi larutan brine seperti pada Tabel 2. Berikut ini:

Tabel 2. Komposisi larutan brine

\begin{tabular}{ccc}
\hline No & Nama Senyawa & Jumlah g/L \\
\hline 1 & $\mathrm{NaCl}$ & 28,5 \\
2 & $\mathrm{CaCl}_{2}$ & 1,16 \\
3 & $\mathrm{MgCl}_{2}$ & 5,2 \\
4 & $\mathrm{NaHCO}_{3}$ & 0,2 \\
\hline
\end{tabular}




\section{3. $\mathrm{Gas} \mathrm{CO}_{2}$}

\section{Proses Persiapan Sampel}

Telah dilakukan percobaan percobaan ini dilakukan untuk mengukur laju korosi pada baja stainlees 410 . Percobaan ini melakukan beberapa tahap proses yaitu

\section{Proses pemotongan sampel}

Pada proses ini dilakukan pemotongan sampel standar, casting, dan forging. Masing - masing sampel di potong dengan ukuran yang sama yaitu $1 \mathrm{~cm}$.

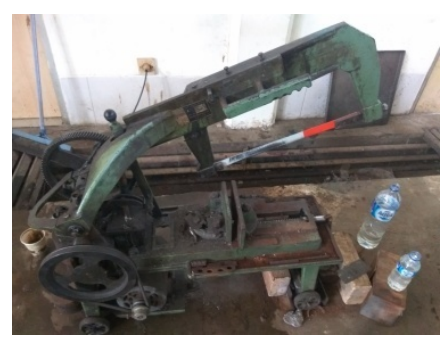

Gambar 1. Proses pemotongan sampel

\section{Proses surface grinding}

pada proses ini dilakukan untuk menghaluskan bagian sampel yang masih terlihat kasar. Setelah sampel di haluskan kemudian sampel akan di rendam selama 13 hari pada larutan brine buatan.

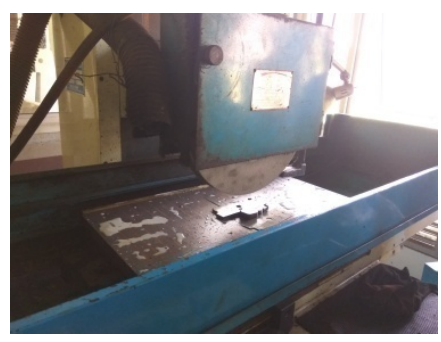

Gambar 2. Proses penghalusan permukaaan sampel

\section{Proses pembuatan larutan brine buatan}

pada proses ini kita melakukan beberapa tahap yaitu menimbang bahan-bahan kimia yang akan dicampurkan seperti, $\mathrm{NaCl}, \mathrm{CaCl}_{2}, \mathrm{MgCl}_{2}$, dan $\mathrm{NaHCO}_{3}$ setelah bahan tersebut dicampurkan dilakukan pengadukan hingga rata setelah di aduk larutan ditambahkan dengan gas $\mathrm{CO}_{2}$ selama 2 jam. Setelah penambahan gas $\mathrm{CO}_{2}$ selama 2 jam larutan brine di ukur $\mathrm{pH}$ awal nya sebelum sampel direndam selama 13 hari [4].

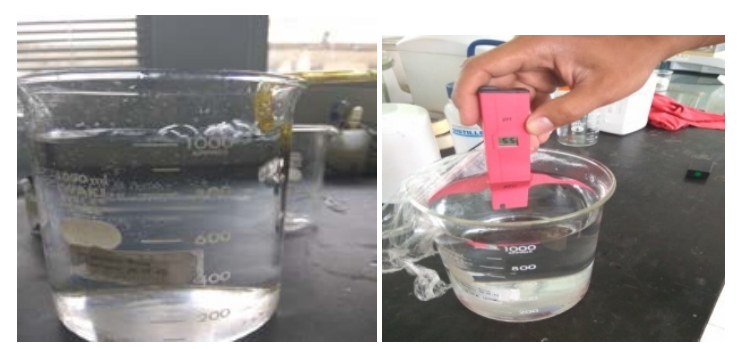


(a)

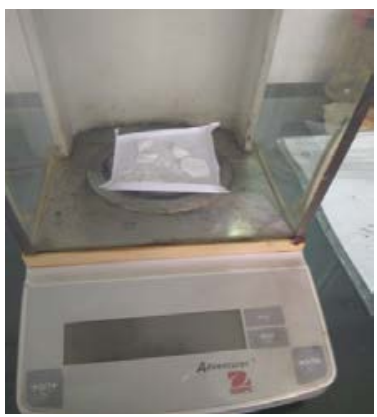

(c) (b)

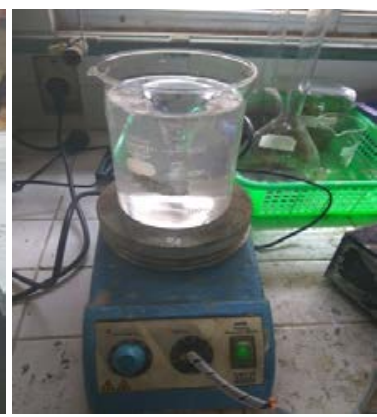

(d)

Gambar 3. (a). Pembuatan larutan brine, (b). Pengukuran pH, (c). Penimbangan bahan kimia, dan (d). Pengadukan larutan.

4. Proses penimbangan sampel

Pada proses ini sebelum sampel di rendam ke dalam larutan brine buatan akan dilakukan penimbangan untuk sampel awal (Mo) dan setelah sampel di rendam selama 13 hari kembali akan diukur berat akhirnya (Ma).

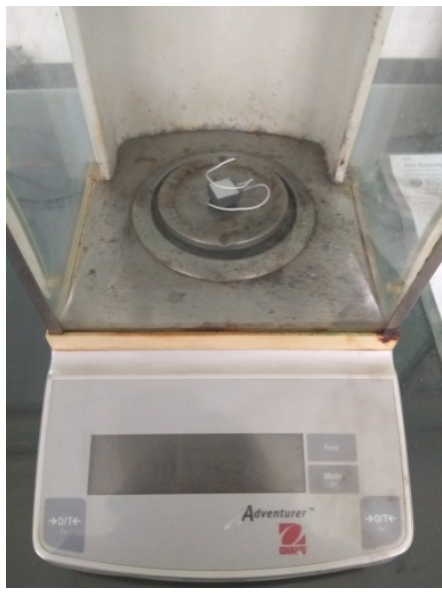

(a)

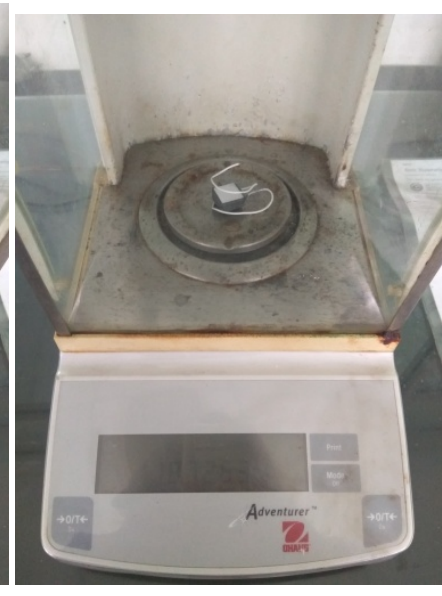

(b)

Gambar4.(a).Penimbangan sampel awal, dan (b). Penimbangan sampel akhir

5. $\quad$ Proses perendaman sampel selama 13 hari

Pada proses ini sampel akan di rendam selama 13 hari. Ketiga sampel tersebut diukur potensial dan $\mathrm{pH}$ larutan nya hal ini dilakukan agar mengetahui seberapa besar korosi yang terjadi pada ketiga sampel tersebut. 


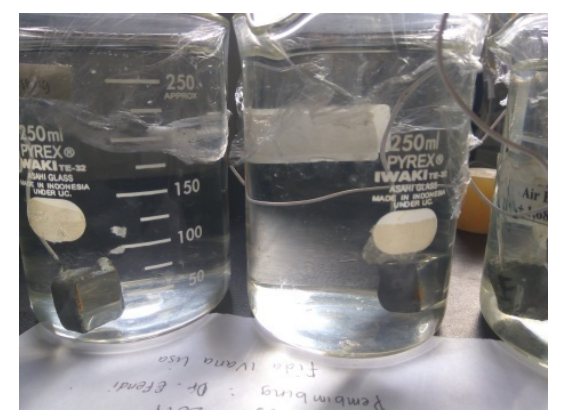

Gambar 5. Proses perendaman sampel selama 13 hari

\section{Diagram Alir Penelitian}

Urutan dari penelitian ini bisa dilihat dari diagram alir yang ada di Gambar 6. Standar pengujian sampel sebelum dan setelah pengujian.

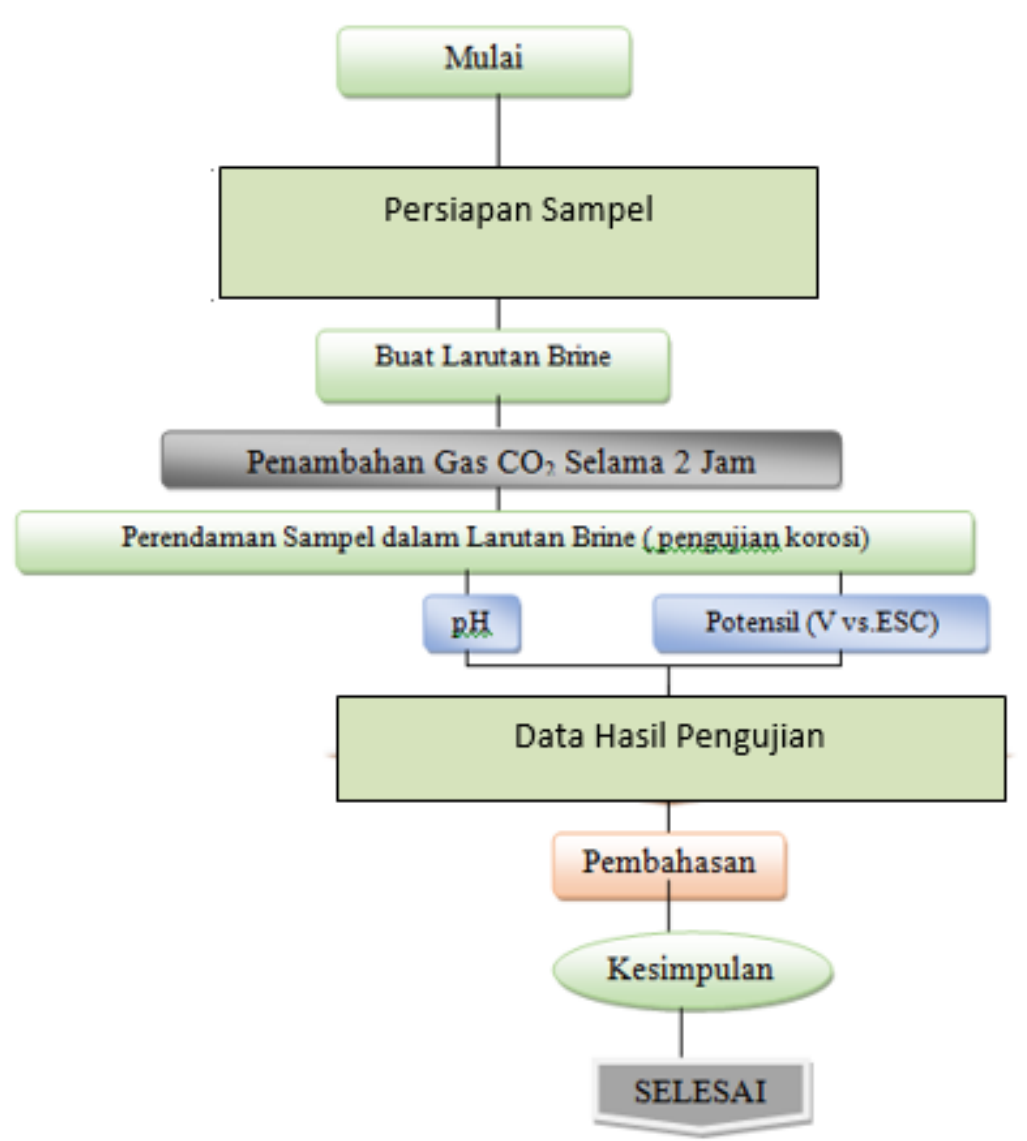

Gambar 6. Diagram alir penelitian 


\section{HASIL DAN PEMBAHASAN}

Adapun data perubahan uji korosi pada percobaan ini :`

Tabel 3. Perubahan massa pada sampel setelah 13 hari perendaman

\begin{tabular}{ccccc}
\hline No & Sampel & Berat awal,Mo & Berat akhir, Ma & Selisih berat, Ma-Mo \\
& AISI 410 & $(\mathrm{~g})$ & $(\mathrm{g})$ & $(\mathrm{g})$ \\
\hline 1 & Standar & 18,4294 & 18,4698 & 0,0404 \\
2 & Casting & 18,7124 & 18,7701 & 0,0577 \\
3 & Forging & 18,7338 & 18,7751 & 0,0413 \\
\hline
\end{tabular}

Dari Tabel 3 di atas, dapat dijelaskan bahwa sampel awal (Mo) adalah massa sampel sebelum direndam dan sampel akhir (Ma) adalah massa sampel yang telah direndam dalam larutan brine buatan selama 14 hari. Hasil pengurangan massa sampel akhir (Mo) dengan massa sampel awal (Ma) adalah (Ma-Mo) yang menunjukkan angka positif yang berarti terjadi penambahan berat. Penambahan berat yang dimaksud bisa terjadi karena ada reaksi logam sampel dengan senyawa oksigen yang ada dalam larutan brain, membentuk produk korosi logam oksida yang biasa disebut produk korosi atau karat.

Tabel 4. Perubahan $\mathrm{pH}$ pada larutan brine

\begin{tabular}{cc}
\hline Hari ke- & pH \\
\hline 0 & 5,5 \\
1 & 6,7 \\
4 & 7,9 \\
5 & 8,1 \\
6 & 8,2 \\
11 & 8,3 \\
12 & 8,4 \\
13 & 8,4 \\
\hline
\end{tabular}

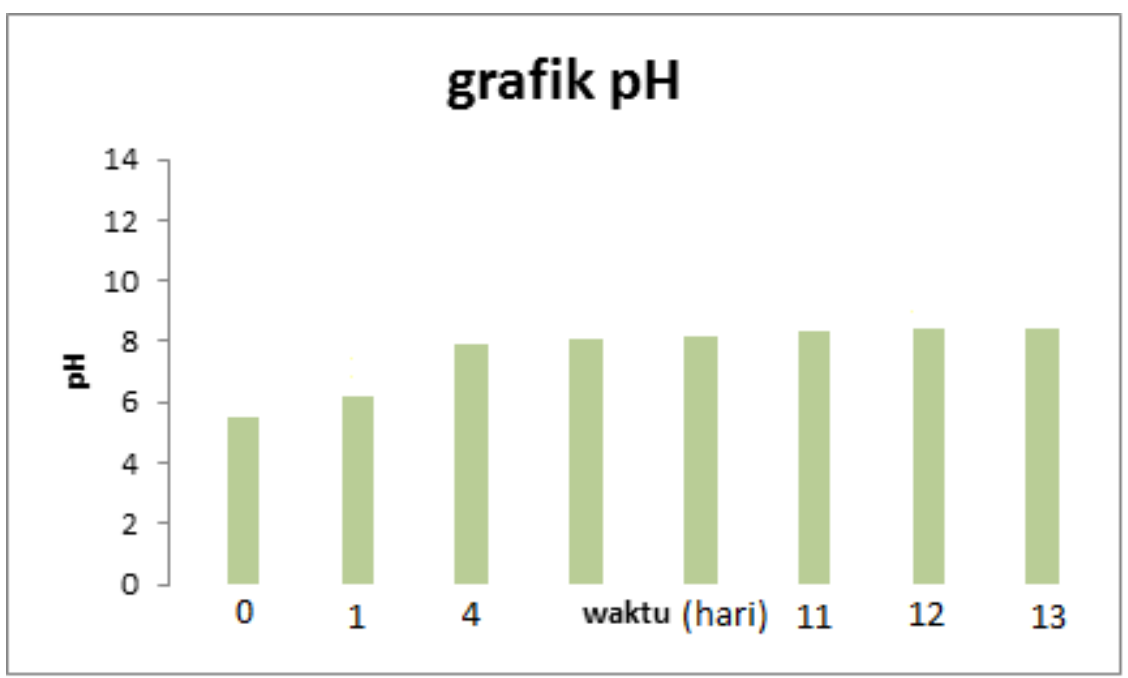

Gambar 8. Hubungan $\mathrm{pH}$ dengan waktu celup 
DariTabel 4 dan Gambar 8 grafik di atas, dapat diketahui bahwa pH awal dari larutan brine buatan adalah 5,5.itu menunjukkan bahwa larutan brine bersifat asam. Sifat larutan asam basa dapat dibagi tiga kelompok, yaitu larutan basa dari pH 0 sampai dengan 6, larutan netral atau garam berkisar dari pH 6 sampai 8 dan larutan basa dari pH 8 sampai dengan $\mathrm{pH}$ 14. Setelah sampel direndam selama beberapa hari terlihat perubahan pH pada larutan yang relatif stabil. Hal ini menunjukkan bahwa semakin sampel terkorosi maka pH larutan brine akan semakin tinggi. Hal ini mengindikasikan, dengan semakin banyak unsur logam yang larut akan meningkatkan $\mathrm{pH}$ larutan yang berarti meningkatkan sifat basa larutan uji.

Tabel 5. Potensial (V vs.SCE) dari setiap sampel

\begin{tabular}{cccc}
\hline Hari ke- & Potensial (v vs.EVC) & Keterangan sampel \\
\hline 0 & - & $0,479 \mathrm{~V}$ & Forging \\
& - & $0,445 \mathrm{~V}$ & Standar \\
& - & $0,419 \mathrm{~V}$ & Casting \\
\hline 1 & - & $0,537 \mathrm{~V}$ & Forging \\
& - & $0,450 \mathrm{~V}$ & Standar \\
& - & $0,461 \mathrm{~V}$ & Casting \\
\hline 4 & - & $0,543 \mathrm{~V}$ & Forging \\
& - & $0,454 \mathrm{~V}$ & Standar \\
& - & $0,468 \mathrm{~V}$ & Casting \\
\hline 5 & - & $0,533 \mathrm{~V}$ & Forging \\
& - & $0,424 \mathrm{~V}$ & Standar \\
& - & $0,455 \mathrm{~V}$ & Casting \\
\hline 6 & - & $0,537 \mathrm{~V}$ & Forging \\
& - & $0,431 \mathrm{~V}$ & Standar \\
& - & $0,450 \mathrm{~V}$ & Casting \\
\hline 11 & - & $0,548 \mathrm{~V}$ & Forging \\
& - & $0,403 \mathrm{~V}$ & Standar \\
& - & $0,433 \mathrm{~V}$ & Casting \\
\hline 12 & - & $0,541 \mathrm{~V}$ & Forging \\
& - & $0,30 \mathrm{~V}$ & Standar \\
& & $0,438 \mathrm{~V}$ & Casting \\
\hline & & & \\
& & & \\
& & &
\end{tabular}

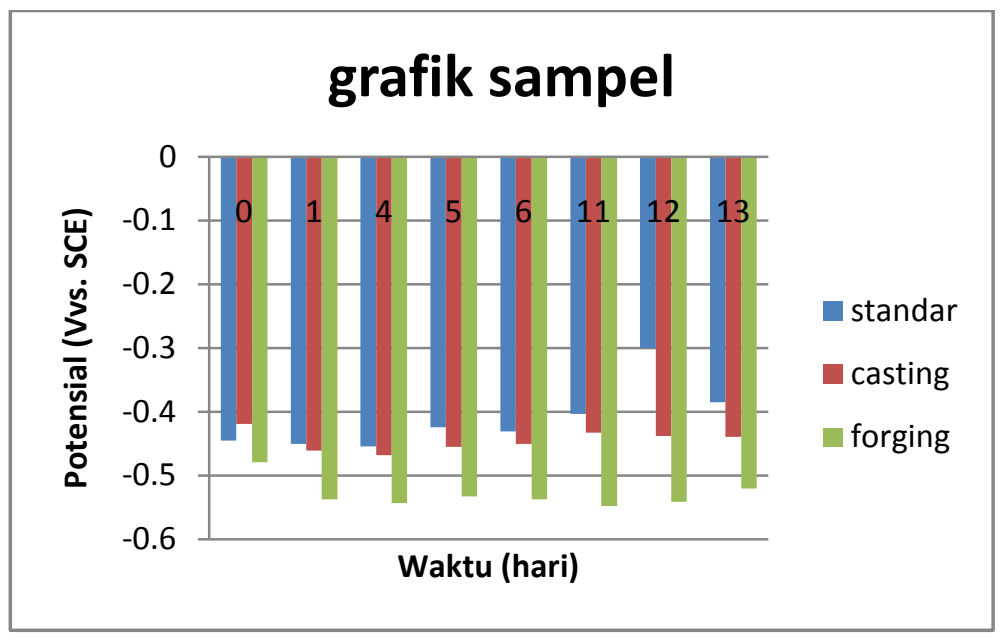

Gambar 9. Hubungan Potensial, Eoc ( V vs SCE) dengan waktu celup (hari) 
Dari data Tabel 5 dan Gambar 9, grafik hubungan potensial Eoc ( V vs SCE) dan waktu celup (hari), dapat diketahui bahwa terjadi perbedaan potensial di antara ketiga sampel hal ini disebabkan karena masing-masing sampel terkorosi selama perendaman berlangsung. Dari Tabel 5 dan grafik pada Gambar 9, dapat diketahui bahwa sampel yang mengalami forging mengalami peningkatan nilai potensial yang lebih tinggi daripada sampel casting dan sampel standar. Demikian juga sampel yang mengalami proses casting mengalami peningkatan nilai potensial yang lebih tinggi daripada sampel casting dan sampel standar

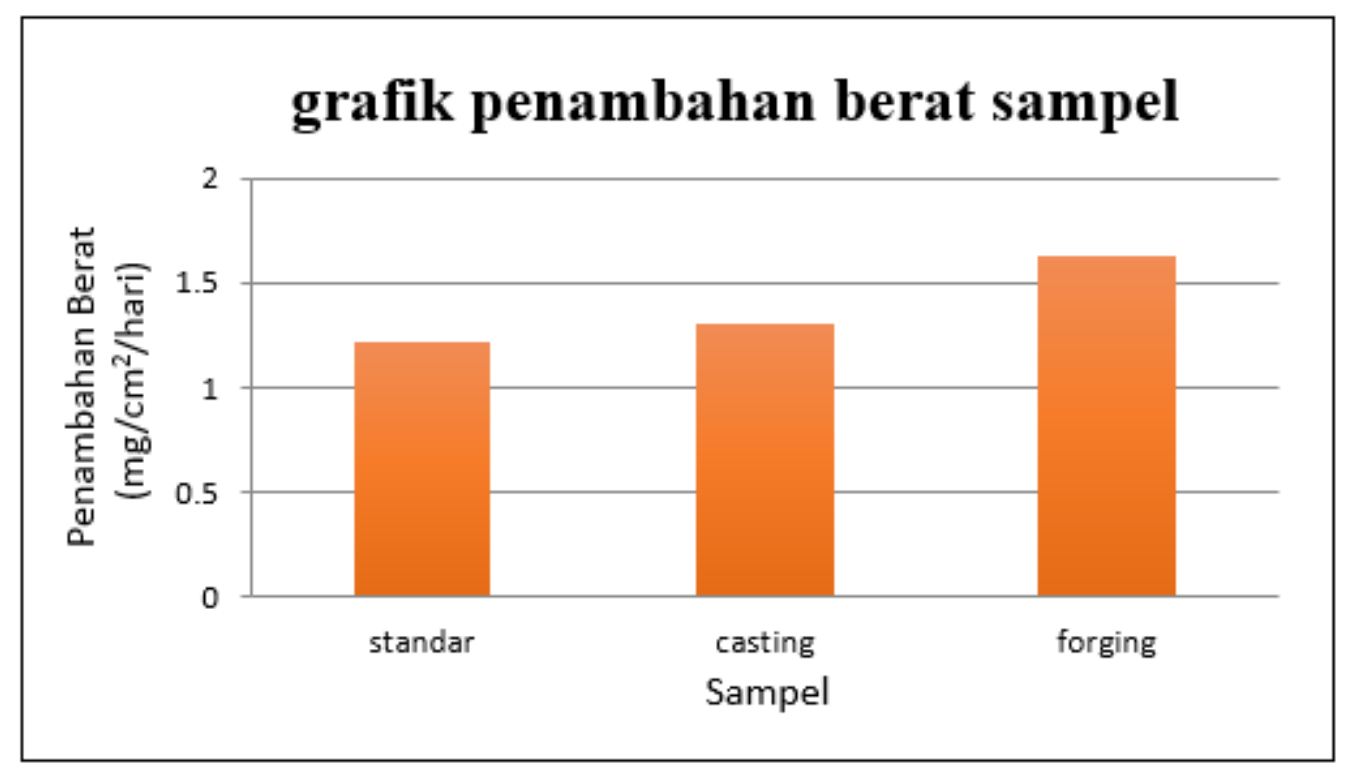

Gambar 10. Penambahan berat sampel setelah direndam didalam larutan brine buatan selama 13 hari

Pada Gambar 10 merupakan hasilpengujian Korosi Baja tahan karat AISI 410 di Media Larutan Brine Buatan. Percobaan ini bertujuan untuk mengukur laju korosi. Hasil yang di dapatkan dari ketiga sampel mengalami penambahan berat yang cukup tinggi, pada samper standar mengalami penambahan berat $1,22 \mathrm{mg} / \mathrm{cm}^{2} / \mathrm{hr}$ setiap harinya, sedangkan pada sampel casting mengalami penambahan berat $1,31 \mathrm{mg} / \mathrm{cm}^{2} / \mathrm{hr}$ setiap harinya, dan pada sampel forging mengalami penambahan berat yg cukup tinggi yaitu $1,63 \mathrm{mg} / \mathrm{cm}^{2} / \mathrm{hr}$ setiap harinya.Hasil pengurangan massa sampel akhir (Mo) dengan massa sampel awal (Ma) adalah (Ma-Mo) yang menunjukkan angka positif yang berarti terjadi penambahan berat. Penambahan berat yang dimaksud bisa terjadi karena ada reaksi logam sampel dengan senyawa oksigen yang ada dalam larutan brain, membentuk produk korosi logam oksida yang biasa disebut produk korosi atau karat.

\section{KESIMPULAN}

Berdasarkan hasil penelitian dalam bentuk data data dan grafik, dapat disimpulakan bahwa:

1. Larutan uji yang berupa larutan brain mengalami peningkatan angka pHnya pada penambahan waktu proses yang berarti terjadi peningkatan angka kebasaannya atau semakin basa.

2. Pada uji korosi, baja SS 410 mengalami peningkatan berat dengan penambahan waktu celup dalam larutan brain yang bisa terjadi karena ada reaksi antara baja dengan senyawa oksigem dalam laturan brain membentuk produk korosi atau karat.

3. Potensial Eoc dari tiga sampel uji, terjadi peningkatan harga potensialnya dari yang terendah ke yang tertinggi yaitu sampel standar, sampel casting dan sampel forging. 


\section{DAFTAR PUSTAKA}

[1] Sudiro, Toto., Tetuo, P Anggito., Kusnandar., Izzudin Hubby., Thosin K.A.Z. 2007. Pelapisan Thermal Barrier Coating (TBC) NiCrAl pada Logam Paduan Berbasis Co. Jurnal Fisika dan Aplikasinya.Vol. 3.No. 2.070202.1-4.

[2] Handbook, A. S. M. 2005. Properties and Selection: Irons, Steels, and High Performance Alloys, 1.Volume 1.

[3] Corporation, A.K Steel. 2007. Product Data Sheet 410 Stainless Steel. A.K Steels.West Chester.

[4] Suheli, A. Noor Setyo HD. Sifat Fisis dan Mekanis Lapisan Ni-Cr pada Permukaan Baja AISI 410.Jurusan Teknik Mesin Fakultas Teknik Universitas. Magelang

[5] Sugiyarta, S., Bayuseno, A. P., \& Nugroho, S. 2012. Pengaruh konsentrasi larutan dan kuat arus terhadap ketebalan pada proses pelapisan nikel untuk baja karbon rendah. ROTASI. Vol.14. No. 4. 23-27.

[6] Girsang, Martin. 2012. Laju Korosi Baja Komersial tanpa dan dengan Lapisan NiCoCr dalam $\mathrm{HCl}$ 10\% Menggunakan Metode Rendam ASTGM G31-72.Skripsi.Medan: Universitas Sumatera Utara. 